CASE REPORT

\title{
Lead poisoning secondary to hyperthyroidism: report of two cases
}

\author{
Marc Klein, Françoise Barbé ${ }^{1}$, Véronique Pascal, Georges Weryha and Jacques Leclère \\ Clinique Médicale et Endocrinologique and ${ }^{1}$ Laboratoire de Biochimie A, CHU de Nancy, Hôpitaux de Brabois, 54500 Vandoeuvre-lès-Nancy, France \\ (Correspondence should be addressed to M Klein)
}

\begin{abstract}
With long-term exposure to lead, lead accumulates in bone, where it is stored for years. These quiescent lead stores are mobilised when increased bone turnover occurs, and latent lead toxicity may then become symptomatic. Although Graves' disease is a common cause of increased bone turnover, to date hyperthyroidism has been implicated in lead poisoning only twice. We describe herein two cases of hyperthyroidism, one caused by toxic multinodular thyroid enlargement, the second by Graves' disease, leading to lead poisoning. Treatment of hyperthyroidism with radioactive iodine cured both hyperthyroidism and lead poisoning and no chelating agent therapy was necessary. Lead poisoning is an important environmental health problem, and physicians must be aware of the endocrine disorders such as hyperthyroidism and hyperparathyroidism that increase bone turnover, favouring lead mobilisation. Atypical symptoms should draw the physician's attention to the possibility of lead poisoning, particularly in workers with occupational exposure to lead and in areas where lead poisoning is endemic.
\end{abstract}

European Journal of Endocrinology 138 185-188

\section{Introduction}

About 1200 deaths were attributed to occupational lead poisoning in England and Wales between 1900 and 1933 (1). During the past 50 years deaths from lead poisoning have become rare, because of progress in diagnosis and legislation aimed at reducing the hazards presented by large-scale industrial use of lead and lead compounds. A large, well-conducted population survey was carried out in the early 1980s to assess blood lead concentrations of lead in areas with differing levels of environmental lead pollution (2). Some of the highest blood lead concentrations were found in areas with high concentrations of lead in the water supply.

Lead is one of the most important and widely distributed pollutants in the environment. Attention has recently focused on the deleterious effects of subclinical lead poisoning, as distinct from acute lead poisoning, which has become rare. Long-term exposure leads to accumulation of lead in bone, where it is stored for years $(3,4)$. These quiescent lead stores are mobilised when increased bone turnover occurs, and latent lead toxicity may then become symptomatic. Although hyperthyroidism increases bone turnover, it has unusually and rarely been implicated in the pathogenesis of lead poisoning, and only two cases have been reported. We describe herein two cases of lead poisoning induced by hyperthyroidism and discuss the pathogenesis of this intoxication.

\section{Case reports}

\section{Patient 1}

An 82-year-old woman with no previous relevant medical history was referred to our clinic for hyperthyroidism. She had mild hypertension, which was not treated, and had had a cholecystectomy and a unilateral oophorectomy for a benign cyst more than 40 years previously. She was admitted to another hospital because of a loss of independence and it was there that paucisymptomatic hyperthyroidism was diagnosed. She was referred to our clinic for aetiological investigation and treatment.

On her admission to hospital, her temperature was $36.6^{\circ} \mathrm{C}$, pulse 80 beats/min and arterial pressure $170 /$ $80 \mathrm{mmHg}$. She was $160 \mathrm{~cm}$ tall; her weight was $47 \mathrm{~kg}$, but had been $50 \mathrm{~kg} 4$ months earlier. Her appetite was good, but she was nervous and anxious. On examination, a multinodular thyroid goitre was found that was diagnosed as toxic by thyroid scintiscanning. Thyrotropin (TSH) concentration was $0.02 \mathrm{mU} / \mathrm{l}$ (normal range (NR) 0.25-4.0); free thyroxin ( $\mathrm{fT}_{4}$ ) concentration was $29.3 \mathrm{pmol} / \mathrm{l}$ (NR 11-25). 
Several symptoms, although also common to hyperthyroidism, suggested possible associated lead poisoning: fatigue, insomnia, irritability, extra pyramidal syndrome, decreased memory recall and ability to concentrate, confusion and labile hypertension. Despite the lack of specificity of such symptoms in an elderly woman, she had lived for a long time in an area of endemic lead poisoning and this led us to investigate possible lead poisoning in her case. Test results were indeed consistent with lead poisoning: delta-aminolaevulinic acid (ALA) dehydratase activity was $0.11 \mu \mathrm{mol}$ (porphobilinogen) $\mathrm{PBG} / \mathrm{ml}$ erythrocytes/h (NR >0.30), erythrocyte protoporphyrin concentration was $2370 \mu \mathrm{mol} / \mathrm{l}$ erythrocytes (NR 300-1120); the $\mathrm{CaNa}_{2}-\mathrm{EDTA}$ provocative test result was $491 \mu \mathrm{g} \mathrm{lead} /$ $24 \mathrm{~h}(\mathrm{NR} \leq 300)$. As the test results suggested that lead poisoning was not severe, we decided to treat the hyperthyroidism and avoid chelation therapy, which may cause kidney damage in the elderly. Propranolol was given in a low dose, and $37 \times 10^{7} \mathrm{~Bq}(10 \mathrm{mCi})$ radioactive iodine was also given. This treatment of the hyperthyroidism alone led to a complete recovery of both thyroid function (TSH concentration $0.73 \mathrm{mU} / \mathrm{l}$ (NR $0.25-4.0) ; \mathrm{fT}_{4}$ concentration $23.9 \mathrm{pmol} / \mathrm{l}$ (NR 11-25)), and lead intoxication (ALA dehydratase activity was $0.35 \mu \mathrm{mol} \mathrm{PBG} / \mathrm{ml}$ erythrocytes/h (NR >0.30); erythrocyte protoporphyrin concentration $1590 \mu \mathrm{mol} / \mathrm{l}$ erythrocytes (NR 300-1120)). The continued increase in concentration of erythrocyte protoporphyrin after treatment was due to the long half-life of erythrocytes. The decrease in erythrocyte protoporphyrin concentrations, associated with normalisation of ALA dehydratase activity, is a sign that lead poisoning has been cured.

\section{Patient 2}

A 46-year-old man with no previous history of lead poisoning was referred to our clinic for a relapse of hyperthyroidism. He was employed as a salesperson in a hypermarket. He had experienced a first episode of Graves' disease 1 year earlier, and had been treated with $37 \times 10^{7} \mathrm{~Bq}(10 \mathrm{mCi})$ radioactive iodine. There was no evidence of lead poisoning during his previous stay in hospital.

The main symptoms on his present admission to hospital were a $7 \mathrm{~kg}$ weight loss, tachycardia (about 120 beats/min), fine resting tremor of both hands, and diarrhoea. On physical examination, he presented with marked 'lid lag', mild exophthalmos (19 mm right, $15 \mathrm{~mm}$ left, NOSPECS IIc, IIIa, IVo, Vo, VIo), a generally enlarged murmuring thyroid gland, and symmetric hyperreflexia. Moreover, he complained of symptoms that had never occurred during former episodes of Grave's disease: abdominal pain, fatigue, insomnia, irritability, and decreased memory recall and ability to concentrate. TSH concentration was $0.02 \mathrm{mU} / \mathrm{l}$ (NR $0.25-4.0$ ); $\mathrm{fT}_{4}$ concentration was $26.8 \mathrm{pmol} / \mathrm{l}$ (NR 11-25).
Serum concentrations of glucose, urea, creatinine and amylase were normal. Cholesterol concentration was slightly low and alkaline phosphatases slightly high $(256 \mathrm{mU} / \mathrm{ml}$ (NR 70-210)). Lead poisoning was diagnosed, although the patient had moved out of the area of endemic lead poisoning 3 years earlier. ALA dehydratase activity was $0.27 \mu \mathrm{mol} \mathrm{PBG} / \mathrm{ml}$ erythrocytes/h (NR >0.30) and erythrocyte protoporphyrin concentration was $1590 \mu \mathrm{mol} / \mathrm{l}$ erythrocytes (NR 3001120); the $\mathrm{CaNa}_{2}$-EDTA provocative test result was greater than $800 \mu \mathrm{g} \mathrm{lead} / 24 \mathrm{~h}(\mathrm{NR} \leq 300)$. Treatment with propranolol and hydroxyzine was begun and a $55.5 \times 10^{7} \mathrm{~Bq}(15 \mathrm{mCi})$ dose of radioactive iodine was given. All symptoms resolved within 3 months after treatment of the hyperthyroidism alone. TSH concentration was $0.18 \mathrm{mU} / \mathrm{l}(\mathrm{NR} 0.25-4.0)$; $\mathrm{fT}_{4}$ concentration was $14.8 \mathrm{pmol} / \mathrm{l}$ (NR 11-25). TSH concentrations were still low 3 months after treatment, because of thyrotrophic inertia. The normalisation of $\mathrm{fT}_{4}$, which occurred in parallel with the disappearance of symptoms, was consistent with the hyperthyroidism being cured despite the low TSH concentration. Lead intoxication was shown to be cured: ALA dehydratase activity was $0.88 \mu \mathrm{mol} \mathrm{PBG} / \mathrm{ml}$ erythrocytes/h (NR $>0.30$ ) and the erythrocyte protoporphyrin concentration was $304 \mu \mathrm{mol} / \mathrm{l}$ erythrocytes (NR 300-1120).

\section{Controls}

To determine whether hyperthyroidism per se could affect ALA dehydratase activity and erythrocyte protoporphyrin concentrations, we measured both parameters in 20 consecutive hyperthyroid patients living outside areas endemic for lead poisoning and with no occupational risk of lead poisoning. None of these analyses gave values outside the normal ranges: mean ALA dehydratase activity was $1.22 \pm 0.25 \mu \mathrm{mol} \mathrm{PBG} / \mathrm{ml}$ erythrocytes/h (NR >0.30) and the erythrocyte protoporphyrin concentration was $824 \pm 174 \mu \mathrm{mol} / \mathrm{l}$ erythrocytes (NR 300-1120).

\section{Discussion}

Lead poisoning not only has industrial and environmental sources, but is endemic in several European areas where the water supply is dispensed via lead pipes. Lead is leached from pipes into drinking water, particularly when the water is acidic and corrosive (5, 6). In adults, barely $10 \%$ of ingested lead is absorbed from the gastrointestinal tract (7). Once absorbed, lead accumulates in three compartments: blood, soft tissues and bone. Constant exposure results in the accumulation of lead in blood (where 95\% of the lead is associated with the erythrocytes) and soft tissues, until a 'steadystate' is reached. Sixty to ninety percent of the body's lead burden is deposited in the skeleton as insoluble, quiescent tertiary lead phosphate $(3,4)$, which may be stored for up to 30 years. 
The best understood toxic effect of lead is its influence on haem synthesis. Lead inhibits two important enzymes implicated in this process: ALA dehydratase and ferrochelatase. Chronic exposure to lead leads to the incorporation of zinc into the porphyrin ring to produce erythrocyte zinc protoporphyrin (ZPP). Several screening tests, based on the effects of lead on haem synthesis, are used to detect chronic exposure to lead; ZPP assay is the most widely used, and measurement of ALA dehydratase activity is used in France $(1,6,8,9)$. In chronic lead poisoning, blood concentrations of lead are not particularly high (10), so blood lead measurements are not useful in screening for chronic lead poisoning. There are few and non-specific symptoms of chronic lead poisoning (abdominal and muscle pain, asthenia, arthralgia, irritability, depression, altered sleep, memory disturbances and hyperactivity in children) (11), so screening tests (ZPP and ALA dehydratase assays) should be performed for all cases of suspected chronic exposure to lead.

Factors that affect calcium distribution also affect lead distribution. For example, high phosphate intake favours storage in bone, and vitamin $\mathrm{D}$ promotes deposition of lead in bones. Parathyroid hormone and dihydrotachysterol mobilise the lead in bones, leading to greater concentrations in blood (10). High alkaline phosphatase concentrations reflect the increase in bone turnover. Several conditions known to increase bone turnover, such as pregnancy $(12-14)$, chemotherapy (15-17), tumorous infiltration of bone (18), or postmenopausal osteoporosis (19), may be associated with the mobilisation of lead in bone stores, leading to chronic lead poisoning. Hyperthyroidism is known to increase bone remodelling (20-22). Therefore, hyperthyroidism may also result in lead poisoning. Nevertheless, until now, only two cases of lead poisoning have been reported in association with hyperthyroidism (23, 24). In the first report, a young patient was wounded by a bullet which remained in his leg for more than 3 years. (23). He experienced hyperthyroidism and his blood lead concentration was high $(>100 \mu \mathrm{g} / 100 \mathrm{ml})$. Treatment with both antithyroid (propylthiouracil) and chelating agents was necessary. The second case report concerned a 37-year-old woman who was exposed to lead in the environment (24). She complained of fatigue, sleep disorders, difficulty in concentrating, abdominal pain, and several signs of hyperthyroidism. Both blood lead and erythrocyte protoporphyrin concentrations were high.

In the cases reported in this article, both patients were living in the Vosges, where water is acidic and unpolluted. Lead pipe lines have been used for many years in this mountainous region, so chronic lead 'administration' via the water supply may, after several years, give rise to lead poisoning. In both our patients, lead poisoning was demonstrated by clinical (albeit non-specific, with several signs common to hyperthyroidism) and biological features, including high blood concentrations of erythrocyte zinc protoporphyrin, low ALA dehydratase activity in circulating blood cells and high lead concentrations in the urine during the $\mathrm{CaNa}_{2}$-EDTA provocative test. Hyperthyroidism per se does not affect ALA dehydratase activity and erythrocyte protoporphyrin concentrations, as none of the tests performed in 20 hyperthyroid patients living outside the area of endemic lead poisoning had ALA dehydratase activity or erythrocyte protoporphyrin concentrations outside the normal ranges.

Our two case reports highlight two phenomena. An increase in bone turnover secondary to hyperthyroidism may lead to the liberation of lead stores from bone into the blood stream and, furthermore, such lead poisoning may develop even when there has been no lead 'administration' for several years, as observed in patient 2 , because the lead stored in bone may be mobilised over a period of years.

These two cases demonstrate that a metabolic disease involving a high rate of bone remodelling is able to generate clinical symptoms of lead poisoning. Lead poisoning is a major environmental health problem and physicians must be aware of the endocrine disorders, such as hyperthyroidism and hyperparathyroidism, that lead to increased bone turnover and possible lead mobilisation. Atypical symptoms should draw the physician's attention to the possibility of lead poisoning, particularly in workers with occupational exposure to lead or in areas where lead poisoning is endemic.

\section{References}

1 Braithwaite RA \& Brown SS. Clinical and sub-clinical lead poisoning: a laboratory perspective. Human Toxicology 19887 503-513.

2 Quinn MJ. Factors affecting blood lead concentrations in the UK. Results of the EEC blood lead survey 1979-1981. International Journal of Epidemiology 198514 420-431.

3 Pounds JG, Long GJ \& Rosen JF. Cellular and molecular toxicity of lead in bone. Environmental Health Perspectives 199191 1732.

4 Rabinowitz MB. Toxicokinetics of bone lead. Environmental Health Perspectives 199191 33-37.

5 Elwood PC, Phillips KM, Lowe N, Phillips JK \& Toothill C. Hardness of domestic water and blood lead levels. Human Toxicology 19832 645-648.

6 Gerson B. Lead. Clinics in Laboratory Medicine $199010441-457$.

7 Rabinowitz M, Wetherhill G \& Kopple J. Kinetic analysis of lead metabolism in healthy humans. Journal of Clinical Investigation 197858 260-270.

8 Duc M, Kaminsky P \& Klein M. Intoxication par le plomb et ses sels. Encyclopédie Médico Chirurgicale 1994 16-007-A-10 1-10.

9 Klein M, Kaminsky P, Duc M-L \& Duc M. Diagnostic et traitements actuels du saturnisme. Revue de Médecine Interne $199415101-$ 109.

10 Winship KA. Toxicity of lead: a review. Adverse Drug Reactions 19898 117-152.

11 Cullen MR, Robins JM \& Eskenazi B. Adult inorganic lead intoxication: presentation of 31 new cases and a review of recent advances in the literature. Medicine 199362 221-247.

12 Klein M, Kaminsky P, Barbé F \& Duc M. Saturnisme et grossesse. Presse Médicale 199423 576-580. 
13 Silbergeld EK. Lead in bone: implications for toxicology during pregnancy and lactation. Environmental Health Perspectives 1991 $9163-70$

14 Thompson GN, Robertson EF \& Fitzgerald S. Lead mobilization during pregnancy. Medical Journal of Australia 1985143131.

15 Beaney RP, Buxton EJ, El-Sharkawi AM, Todd AC, Braithwaite RA, Somervaille LJ et al. Cisplatin invoked lead mobilisation studies. British Journal of Cancer 199061 169-170.

16 El-Sharkawi AM, Cobbold S, Evans CJ, Chettle DR, Morgan WD, Jaib MBM et al. Unexpected mobilisation of lead during cisplatin chemotherapy. Lancet $19861249-250$.

17 Tothill P, Matheson LM, McKay K \& Smyth JF. Mobilisation of lead by cisplatin. Lancet 198921342.

18 Brown A \& Tompsett SL. Poisoning due to mobilization of lead from the skeleton by leukaemic hyperplasia of bone marrow. British Medical Journal 19452 764-765.

19 Silbergeld EK, Schwartz J \& Mahaffey K. Lead and osteoporosis: mobilization of lead from bone in postmenopausal women. Environmental Research 198847 79-94.

20 Allain TJ, Chambers TJ, Flanagan AM \& McGregor AM.
Triiodothyronine stimulates rat osteoclastic bone resorption by an indirect effect. Journal of Endocrinology 1992133 327331.

21 De Menis E, Da Rin G, Roiter I, Legouini P, Foscolo G \& Conte N. Bone turnover in overt and subclinical hyperthyroidism due to autonomous thyroid adenoma. Hormone Research 199237 217220.

22 Hasling C, Eriksen EF, Charles P \& Mosekilde L. Exogenous triiodothyronine activates bone remodeling. Bone 19878 65-69.

23 Cagin CR, Diloy-Puray M \& Westerman MP. Bullets, lead poisoning, and thyrotoxicosis. Annals of Internal Medicine 1978 89 509-511.

24 Goldman RH, White R, Kales SN \& Hu H. Lead poisoning from mobilization of bone stores during thyrotoxicosis. American Journal of Industrial Medicine 199425 417-424.

Received 14 July 1997

Accepted 3 November 1997 